\title{
Design the High-frequency DC-DC Converter with Integrated Coupled Inductor and Current-Balancing-Transformer
}

Dou, Yi; Ouyang, Ziwei; Andersen, Michael A.E.

Published in:

Proceedings of 35th Annual IEEE Applied Power Electronics Conference and Exposition

Link to article, DOI:

10.1109/APEC39645.2020.9124329

Publication date:

2020

Document Version

Peer reviewed version

Link back to DTU Orbit

Citation (APA):

Dou, Y., Ouyang, Z., \& Andersen, M. A. E. (2020). Design the High-frequency DC-DC Converter with Integrated Coupled Inductor and Current-Balancing-Transformer. In Proceedings of 35th Annual IEEE Applied Power Electronics Conference and Exposition (pp. 2610-2616). [9124329] IEEE. https://doi.org/10.1109/APEC39645.2020.9124329

\section{General rights}

Copyright and moral rights for the publications made accessible in the public portal are retained by the authors and/or other copyright owners and it is a condition of accessing publications that users recognise and abide by the legal requirements associated with these rights.

- Users may download and print one copy of any publication from the public portal for the purpose of private study or research.

- You may not further distribute the material or use it for any profit-making activity or commercial gain

- You may freely distribute the URL identifying the publication in the public portal 


\section{Design the High-frequency DC-DC Converter with Integrated Coupled Inductor and Current-Balancing-Transformer}

\author{
Yi Dou \\ Department of Electrical Engineering \\ Technical University of Denmark \\ Kgs. Lyngby, Denmark \\ yidou@elektro.dtu.dk
}

\author{
Ziwei Ouyang \\ Department of Electrical Engineering \\ Technical University of Denmark \\ Kgs. Lyngby, Denmark \\ zo@elektro.dtu.dk
}

\author{
Michael A.E. Andersen \\ Department of Electrical Engineering \\ Technical University of Denmark \\ Kgs. Lyngby, Denmark \\ ma@elektro.dtu.dk
}

\begin{abstract}
This paper presents a design for a high-frequency DC-DC converter with the coupled inductor and integrated current balancing transformer. The converter can deliver $32 \mathrm{~W}$ from $12 \mathrm{~V}$ intput to the $4 \mathrm{~V}$ output. $\mathrm{A}$ high efficiency and high power density are achieved by ZVS turn-on and the magnetic integrated. In order to deliver a $6 \mathrm{~A}$ rated output current, a twophase QSW Buck converter operating at the synchronous mode is seleted as the topology to reduce the conduction loss both for the switches and the windings. The current unbalancing issue is solved by an integrated magnetic component with a customized core. The semiconductors selection and the core design are also discussed in the paper. A $1 \mathrm{MHz}$ prototype is built to verify the design process. The prototype achieves $97.45 \%$ efficiency at 4 V/ 6 A output and the ZVS turn-on capability is also verified experimentally.
\end{abstract}

Index Terms-High-frequency DC-DC converter; Converter design; ZVS Buck converter; Planar magnetics; Coupled inductor; Current balancing transformer

\section{INTRODUCTION}

With the rapid development of consumer electronics, the new requirements for the low-power battery charging circuit come up, including higher output capability, wide input range and higher efficiency. A typical battery charging system for consumer electronics is illustrated in Fig.1. It is noticed that after the adapter stage, a DC-DC power converter is needed to regulate the power from the adapter to the battery. Conventioanl DC-DC power converter for low-power battery charging application can not meet all the emerging requirements thus needed to be further improved [1], [2]. The QSW Buck converter is the most common topology for this application and with the new GaN HEMTs and ferrite materials, it can achieve a high efficiency and high power density [3]-[6]. However, at high output current operation, the efficiency is still limited by conduction loss from switches and the magnetics windings. Multi-phase converters with integrated magnetic components are one solution to deal with the high conduction loss, but it suffers from the complex control system and higher components' cost [7], [8].

In this paper, a low-power DC-DC converter is designed dedicated for battery charging in consumer electronics applications. The rated input of the charger is $12 \mathrm{~V}$ and the

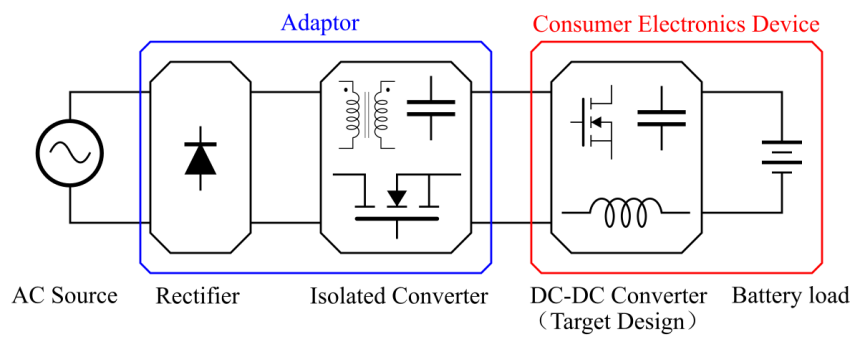

Fig. 1. Illustration of a typical battery charger for consumer electronics devices.

rated output is $4 \mathrm{~V} / 6 \mathrm{~A}$. To pursure a high efficiency of the converter, two identical power stage are connected in parallel to reduce the conduction loss both for the switches and the magnetic windings. In addition, the ZVS turn-on is also pursued for the high frequency operation to minimize the switching loss for the semiconductors. Accordingly, an integrated PCB magneitc struture was proposed to further shrink the size of the magnetic components and to balance the power between two power stages. The proposed structure has been reported in [9]. Thus, this paper focuses on the circuit design consideration for the converter. First, a topology comparison between interleaved operation and the synchronous operation is presented in section II; And in section III, the current unbalance issue is justified and the solution with the integrated magnetics is intruduced. The design considerations, including the components selection and magnetics design, are presented in section IV. In section V, this solution and the circuit design are experimentally verified and the section VI concludes the paper.

\section{Two-Phase Synchronous Buck CONVERTER WITH COUPLED INDUCTOR AND INTEGRATED CURRENT-BALANCING-TRANSFORMER (CBT)}

\section{A. ZVS Turn-On Realization for Half-Bridge Configuration}

At high-frequency operation, ZVS turn-on for the switches can significantly reduce the switching loss. The basic configuration for ZVS turn-on is two switches in half-bridge with and 
inductive element connected to the switch-node, as illustrated in Fig. 2 (a). The key waveforms during the ZVS transition is shown in 3 (b). Before $t_{1}$ the low-side switch $Q_{2}$ is turn-on and the high-side switch $Q_{1}$ is turn-off. Thus voltage of the highside switch $V_{Q 1}$ equals to the DC voltage $V_{g}$ and the voltage of the low-side switch $V_{Q 2}$ equals to zero. At $t_{1}$, the current on the inductive element $L$ must conduct reversly to provide the excitation for the ZVS transition. During the transition $t_{1}$ to $t_{2}$, the $V_{Q 2}$ increases to $V_{g}$ while $V_{Q 1}$ decreases to zero. Finally at $t 2$. the ZVS transition finished with minimized switching loss on the switches. It can be found that the ZVS structure is natually included in the Buck converter and as long as the current of the inductor in the Buck converter can be discharged to be minus, the ZVS turn-on can be achieved.

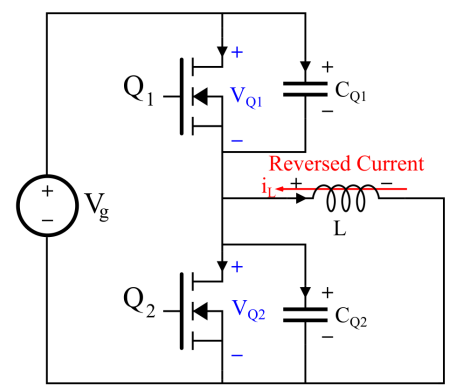

(a)

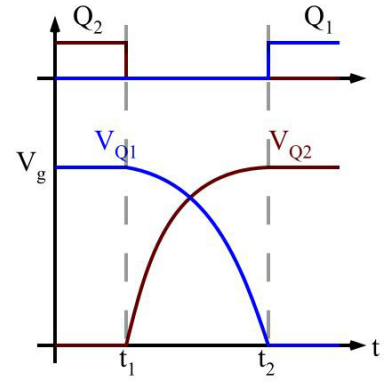

(b)
Fig. 2. (a) Basic circuit configuration of ZVS turn-on (b) Key waveforms of the ZVS transition.

\section{B. Topology Selection and Evaluation}

Buck converter is the most common step-down DC-DC converter with an intrinsic ZVS structure for low-power applications. A basic buck converter only consists of two part: two switches in half-bridge configuration chopping the input voltage and an LC low-pass filter smoothing the ripple. With high-frequency operation in DC-DC converters, the ZVS turnon has been proposed to reduce turn-on loss for switches. It was reported that with the ZVS turn-on achieved, the switching loss can be neglected on GaN HEMTs [10]. Therefore, the conduction loss on switches and windings of magnetic components would dominate the total power loss on a converter, whose loss models are given in (1) and (2):

$$
\begin{gathered}
P_{\text {conduction }}=I_{R M S}^{2} R_{d s o n} \\
P_{\text {winding }}=I_{A C}^{2} R_{D C}+I_{D C}^{2} R_{D C}
\end{gathered}
$$

, where $P_{\text {conduction }}$ is the switch's conduction loss; $I_{R M S}$ is the RMS current on the switch; $R_{d s o n}$ is the conduction resistance of the switch; $P_{\text {winding }}$ is the winding conduction loss for the magnetic component; $I_{A C}$ and $I_{D C}$ are the RMS $\mathrm{AC}$ components and the RMS DC components of the current of the winding; and $R_{A C}$ and $R_{D C}$ are the equivalent $\mathrm{AC}$ resistance and the equivalent $\mathrm{AC}$ resistance of the winding. To pursue a maximum operation efficiency at high current output, a two-phase paralleled buck converter is adopted in this design, in which the power loss can be directly reduced by half if the power are distributed equally between two phases.

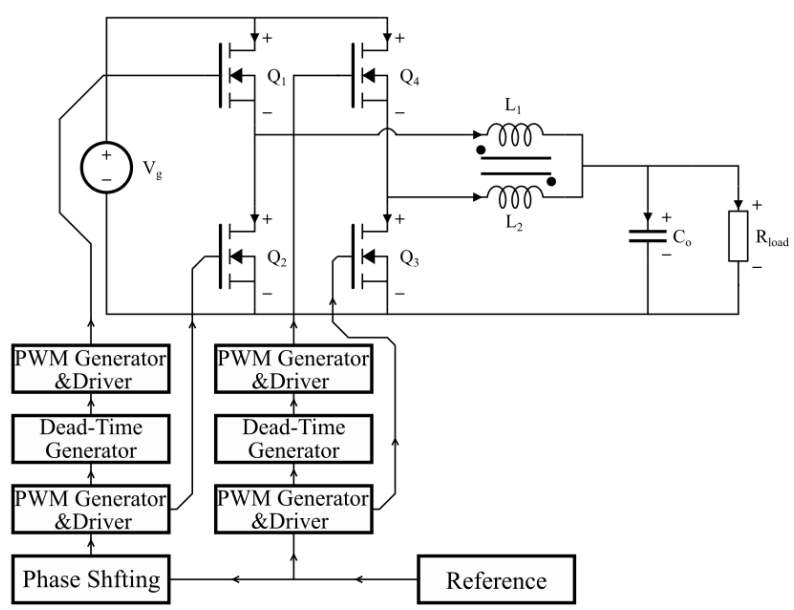

(a)

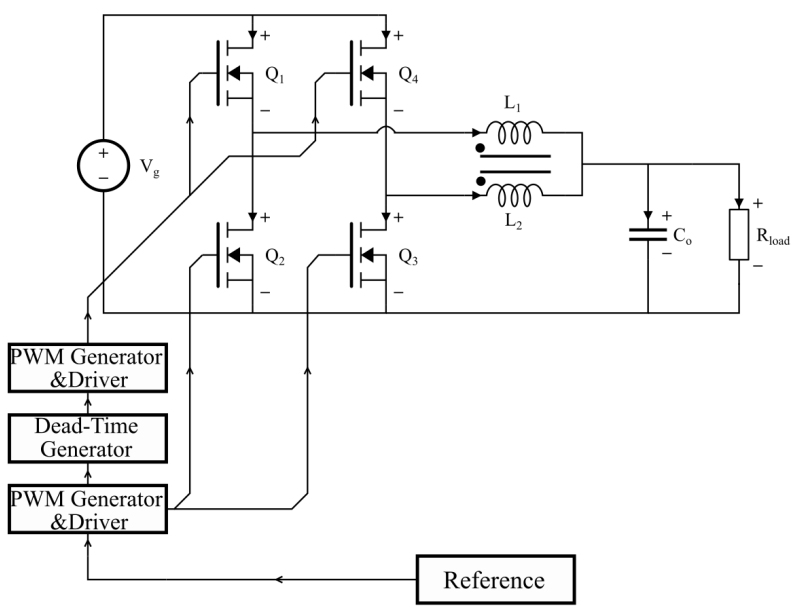

(b)

Fig. 3. Two-phase Buck converter (a) with interleaved operation and reversely coupled inductor (b) with synchronous operation and directly coupled inductor.

Interleaving operation and coupled inductor (CI) have been introduced in multi-phase DC-DC converters for higher power density and reducing the current ripple. In [11], the two-phse buck converter under interleaving operation and with a negative coupled inductor was demostrated for a high efficiency and a size reduction of the magnetic component. However, with the interleaved operation, the dead-time for each phase in the converter need to be precisely controlled seperately, which requires high-performance controllers. Besides, by coupling two inductors together, not only the number of cores can be reduced as one, but also the RMS current of both the windings and semiconductors can be reduced. Nevertheless, with interleaving operation, the control system of the converter would be more complicated. As shown in Fig.3 (a), a phase shifting circuit and two dead-time generator need to be implemented in the converter, which even requires high-performance 
controller at high-frequency operation. As a comparision, another concept for the application is to design the two phases working at the synchronous modes, which means only one PWM generator and one dead-time generator are needed, as illustrated in Fig.3 (b). In the synchronous mode, only the directly coupled inductor can be adopted for minimizing the core's quantity. In addition, the synchronous mode can achieve a simplified control structure and high efficiency only when the current can be distributed equally between two phases. In the design, the two-phase buck converter in synchronous mode with directly coupled inductors is selected due to its simple structure for a minimized size.

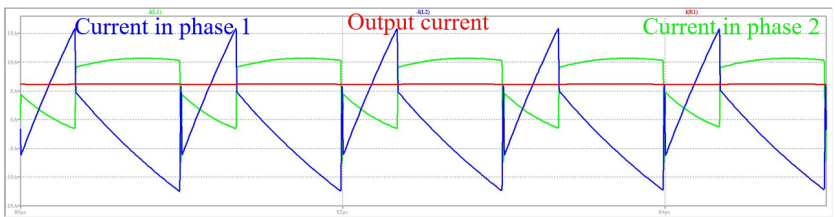

(a)

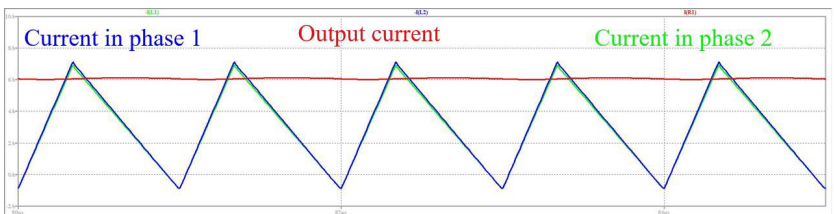

(b)

Fig. 4. Simulation results of two-phase Buck converter with directly coupled inducotr (a) without CBT (c) with a CBT in series.

\section{Current Unbalancing Issue and Solution}

During the implementation of two identical phases for the converter, a parameters ' error, including the conduction resistance of the switches, the equivalent inductance of two phases and the winding resistance of two phases, is inevitable and it causes a current unbalancing through two phases. A simulation demonstration of this deduced current balancing are presented. In the simulation, an inductance difference of $2 \%(5 \mathrm{nH} / 360 \mathrm{nH})$ is set on the coupled inductor and all the switches are modelled with their parasitic parameters and work at $1 \mathrm{MHz}$ switching frequency. In the Fig.4 (a), a significant unbalanced current are illustrated for phase 1 in blue and for phase 2 in green while the output current is in red with the output capacitor of $30 \mathrm{uF}$. The significant unbalanced current will cause much loss difference on the switches between two phases and also, the ZVS turn-on for the two high-side switches will lost, which may lead to a destroy for the semiconductors. In the design, the current balancing transformer (CBT) is implemented in the two-phase converter to solve the problem, which is connected in series with the directly coupled inductor, as shown in Fig.5. As shown in Fig.4 (b), the simulated current in the phase 1 (in blue) and in the phase 2 (in green) are kept identical to maintain a good current balancing and the identical reversed current can help to realize the ZVS turn-on for two high-side switches. In addition, the balanced current can reduced the difficulty for thermal management and heat dissipation design for the converter.

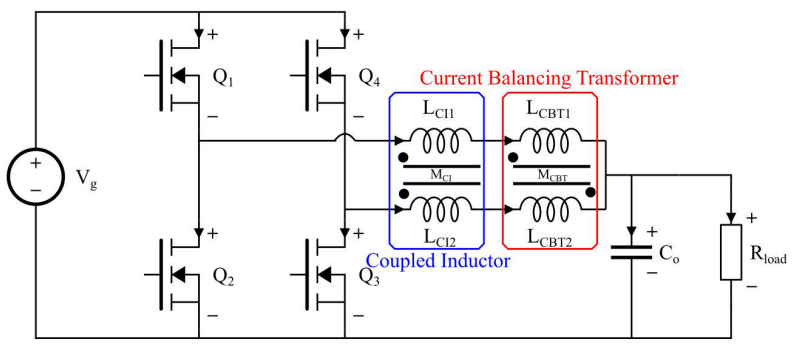

Fig. 5. Topology of the two-phase synchronous Buck converter with CI and integrated CBT.

In order to further minimize the size of the magnetic component, a integrated structure in [9] is used for the design, whose configuration is shown in Fig.6. A detailed winding configuration is illustrated in Fig. 7. As illustrated in Fig. 7, the two CI windings (marked in red) are directly coupled while the two CBT windings (marked in blue) are reversely coupled. The CI windings are connected in series with the CBT windings by the connection windings (marked in brown), thus all the magnetics devices in the topology as Fig.5 are integrated in one four-leg magnetic core.

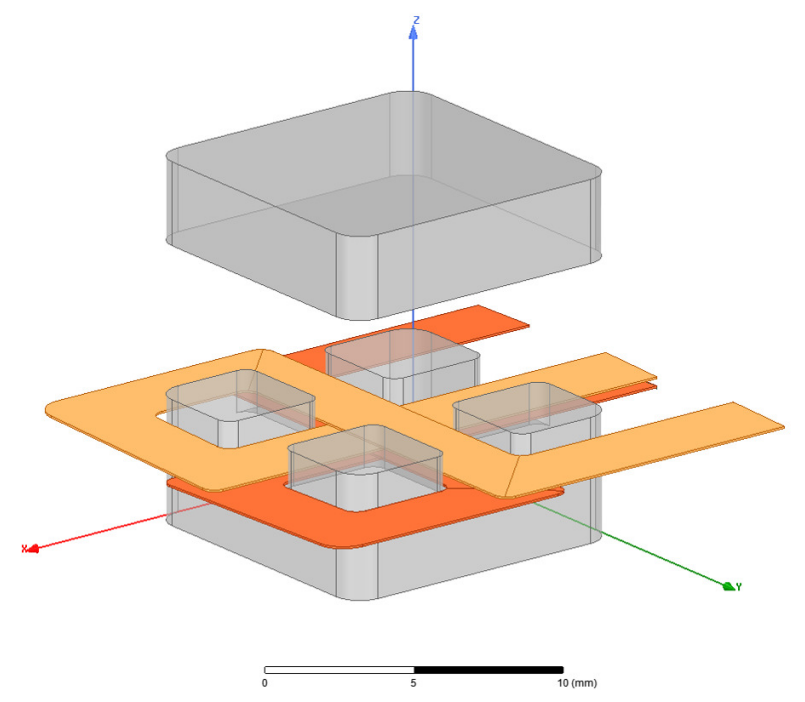

Fig. 6. Overview of the integrated mangetic device.

\section{Circuit Design Considerations}

\section{A. Switches Selection}

Choosing appropriate switches becomes trickier with the ZVS turn-on and GaN FETs especially during high-frequency operation in the design. With ZVS turn-on achievement of the semiconductors, the loss model for the swithces only consists of two parts: turn-off loss and conduction loss. The turn-off loss can be calculated by

$$
P_{\text {turn-off }}=\frac{I_{\text {off }}^{2} t_{\text {off }}^{2}}{48 C_{\text {oss }}} f_{s}
$$



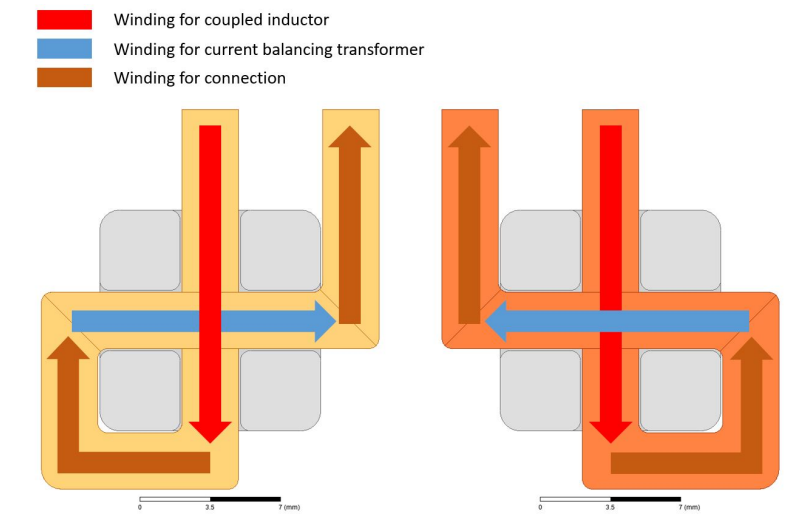

Fig. 7. Winding configuration for the coupled inductor with integrated CBT.

TABLE I

GAN HEMT CANDIDATES AND THEIR KEY PARAMETERS

\begin{tabular}{l|ccccc}
\hline \hline & $V_{d s}(V)$ & $R_{d} s-o n(m \Omega)$ & $Q_{g}(n C)$ & $C_{o s s}$ at $12 \mathrm{~V}(p F)$ & \\
\hline EPC2100 & 30 & 8.2 & 3.6 & 350 & High-side \\
\hline & 30 & 2.1 & 15 & 1900 & Low-side \\
\hline EPC2023 & 30 & 1.45 & 19 & 1700 & \\
\hline EPC2015C & 40 & 4 & 8.7 & 920 & \\
\hline EPC2030 & 40 & 2.4 & 17 & 1500 & \\
\hline EPC2024 & 40 & 1.5 & 18 & 2100 & \\
\hline \hline
\end{tabular}

, where $I_{o f f}$ is the instant current when the switch is turnedoff; $t_{\text {off } f}$ is the falling time of the current; $C_{\text {oss }}$ is the output capacitor of the switch and $f_{s}$ is the switching frequency. The conduction loss can be calculated by

$$
P_{\text {conduction }}=I_{\text {con-RMS }}^{2} R_{d s-o n}
$$

, where $I_{c o n-R M S}$ is the RMS current conducted on the switch and the $R_{d s-o n}$ is the conduction resistance of the switches. In order to select the switches with the lowest power loss, the power loss are swept among several candidate GaN HEMTs, whose key parameters are shown in Table I. The calculated power loss based on the loss models on the high-side and low-side switches under a sweeping switching frequency are shown in Fig.8. It can be found that for both high-side and low-side switces, the GaN HEMT EPC2015C could give the lowest power loss at $1 \mathrm{MHz}$ thus it is selected in the prototype.

\section{B. Simplified Magnetic Design}

A simplified magnetics design for the integrated structure is presented for the application, with $12 \mathrm{~V}$ rated input and $4 \mathrm{~V}$ rated output. The conventional optimization design for inductors focuses on balancing among winding loss, core loss and energy storage, then the optimized effective permeability can be derived to determine the shape of the magnetic core, the number of turns and the length of air-gap [12] However, among high-frequency Ferrite applications, the accessible maximum flux density $\left(B_{\max }\right)$ of the material normally is much lower than its saturation flux density. Thus, the saturation flux density should be removed from the three main limitations for an optimized design. Correspondingly, due to enhanced skin effect, proximity effect and fringing effect at high-frequency operation, the winding loss usually dominates the total power

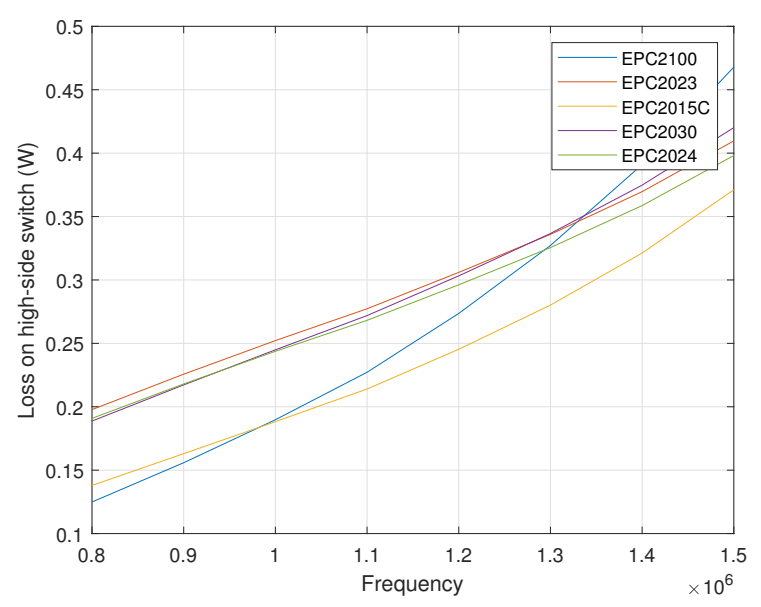

(a)

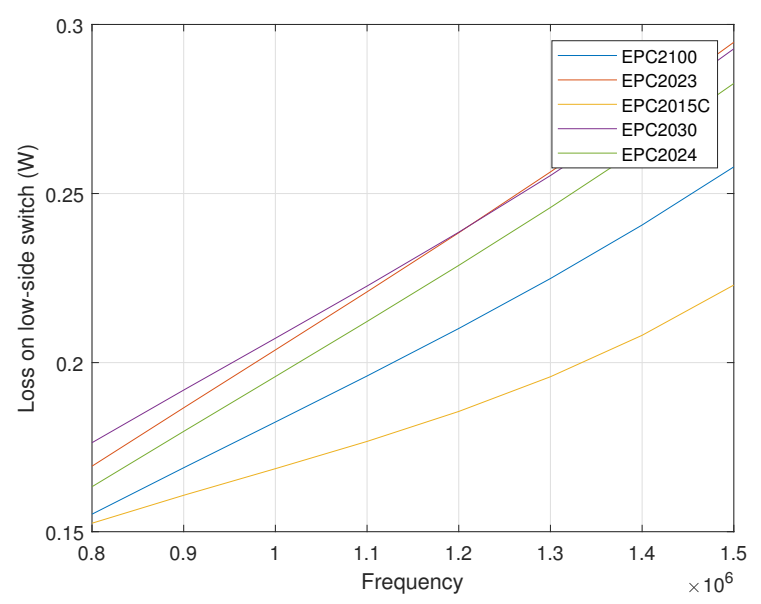

(b)

Fig. 8. Calculated power loss on switches of the converter (a) for high-side switches (b) for low-side switches.

loss especially at high-current output applications. Thus, a simplified magnetics design based on Faraday's law is proposed with customizing the cross section of the integrated structure. Firstly, the material of the core is selected based on the figureof-merit among several candidate ferrite materials. In Fig9, the figure-of-merit (FOM) under a specific core loss density, which is defined in (5) is shown to evaluate the materials. In (5), the $f$ is the operational frequency of the current waveform and $\Delta B$ is the ripple of the magnetic flux. Normally with a higher FOM, the materials can store or tranfer more power with the same core loss produced. Based on Fig.9, the ML91S from HITACHI Metal is selected as the core material in this design.

$$
F O M=f \times \Delta B
$$

In order to limit the core loss of a specified material, the maximum flux ripple $(\Delta B)$ of the core is set as $160 \mathrm{mT}$. And then the effective area of the core can be calculated as the 
function of the switching frequency in a ZVS Buck converter based on:

$$
V_{o}=\frac{\Delta B A_{e} f_{s} N}{(1-D)}
$$

, where $\Delta B$ is the limited ripple of the magnetic flux; $A_{e}$ is the effective area of core; $f_{s}$ is the switching frequency of the converter; $N$ is the number of the turns and $D$ is the duty-cycle. It can be found that the core-loss is only depended on the switching frequency, the number of turns and the effective area under the rated operation. And the length of the air-gap is used to determine the inductance to adapt different output current. With the design specification of $12 \mathrm{~V}$ input and $4 \mathrm{~V}$ output, the effective area is swept by the various switching frequency and the results are shown in Fig.10. It can be found that with the inceased switching frequency and higher number of turns, the effective area of the core can be reduced. However, with higher number of turns in planar magnetics, the increasing number of layers will cause a significant proximity effect, which will increase the AC loss on the windings. Finally, the number of turns is selected as 1 and the switching frequency is selected as $1 \mathrm{MHz}$ to balance the footprint and the winding loss of the design, where the corresponding effective area is $32 \mathrm{~mm}^{2}$.

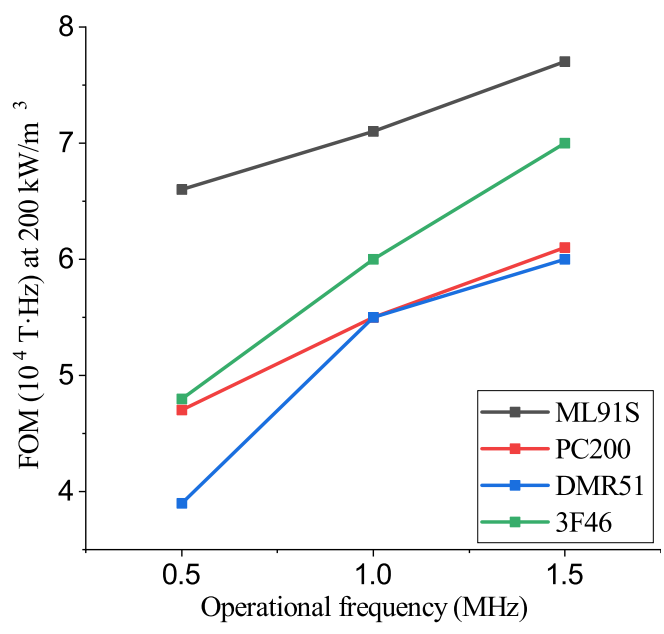

Fig. 9. Figure of merit for the material candidates.

\section{Prototype Assembling And Experimental RESULTS}

\section{A. Planar Mangetics with Customized Core}

As presention in Section III, the effective area of the core is designed as $32 \mathrm{~mm}^{2}$ and the number of the turns is selected as 1 . Then a customized four-leg ferrite core is manufatured with PCB windings. The geometry of the customized core is illustrated in Fig. 11 (a) and the photo of the core is shown in Fig.11 (b). In Fig.12, the model of the copper windings are shown from top-view and bottom-view. In this design an 8-layer PCB is adopoted to make the windings paralleled

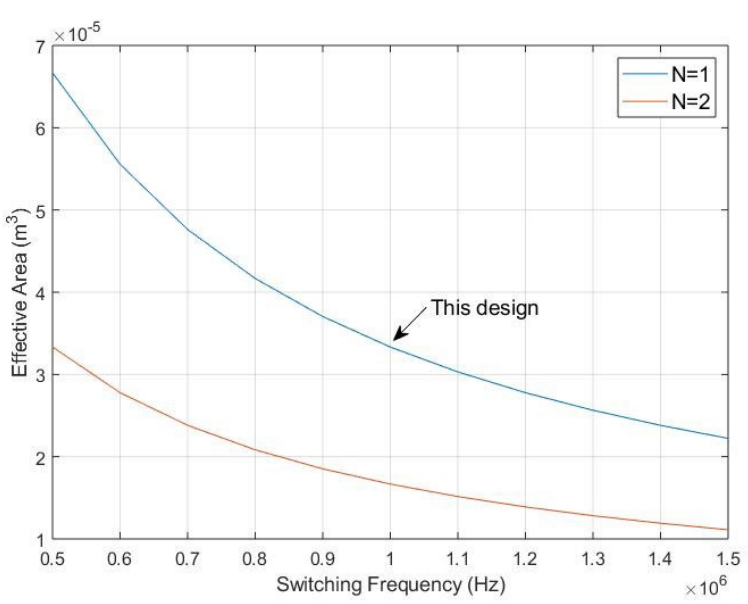

Fig. 10. Effective area of the core as a function of switching frequency.

to balance the manufacturing cost and the winding loss. In Table I, the inductance of the coupled inductor and the CBT are given from calculation, FEA sumulation and small-signal measurement.

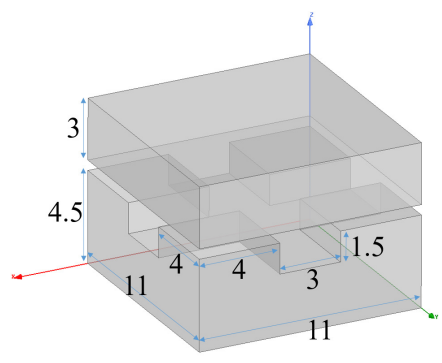

(a)

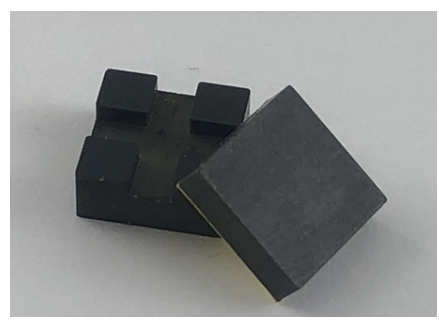

(b)
Fig. 11. (a) Geometry annotation of the customized ferrite core (b) Photo of the customized ferrite core.
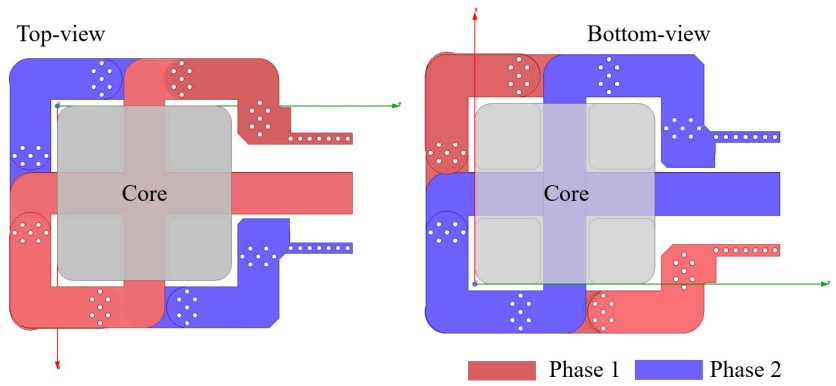

Fig. 12. PCB winding configuration for the coupled inductor with integrated CBT.

\section{B. Testing of the Prototype}

A $1 \mathrm{MHz}$ prototype is built by following the design procedures and the photo of the prototype is shown in Fig.13. The key components of the prototype are presented in Table III. The prototype was tested under following specifications: the 
TABLE II

INDUCTANCE CALCULATION, SIMULATION AND MEASUREMENT RESULTE OF THE MAGNETIC COMPONENT.

\begin{tabular}{l|ccc}
\hline \hline Unit: $\mathrm{nH}$ & Calculation & Simulation & Measurement \\
\hline$L_{C I 1} / L_{C I 2}$ & 187.14 & $175.64 / 173.32$ & $184.34 / 186.45$ \\
$M_{C I}$ & 187.14 & 167.36 & 174.33 \\
$L_{C B T 1} / L_{C B T 2}$ & 187.14 & $180.54 / 180.36$ & $182.64 / 184.34$ \\
$M_{C B T}$ & 187.14 & 178.98 & 176.76 \\
\hline \hline
\end{tabular}

TABLE III

KEY PARAMETERS OF THE $1 \mathrm{MHZ}$ PROTOTYPE

\begin{tabular}{lll}
\hline \hline Component & Value & Description \\
\hline Switches $\left(Q_{1}-Q_{4}\right)$ & EPC2015C & 40V GaN HEMT \\
Gate drivers & LMG1205 & Half-bridge gate driver \\
Core & EI-11-7.5 & Customized core \\
$C_{i n}$ & $25 \mathrm{~V} / 2.2 \mathrm{uF} \times 8$ & Input capacitors \\
$C_{o}$ & $10 \mathrm{~V} / 1 \mathrm{uF} \times 5$ & Output capacitors \\
\hline \hline
\end{tabular}

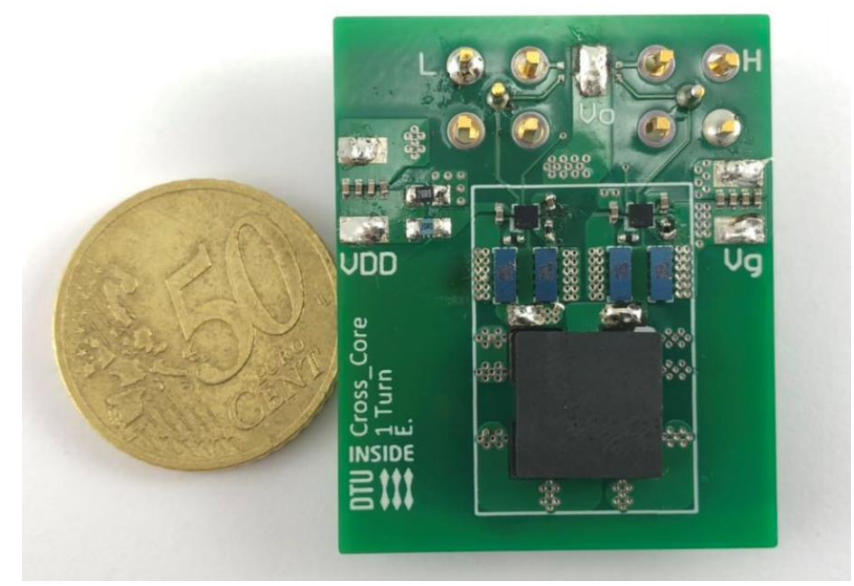

Fig. 13. Photo of the $1 \mathrm{MHz}$ prototype with GaN HEMTs and the planar magnetic component.

input voltage is from $6 \mathrm{~V}$ to $12 \mathrm{~V}$ and the output is set as 4 $\mathrm{V}$. The maximum output power is $32 \mathrm{~W}$.

During the testing, only one PWM input is given to both of the phases and also the two phses use the identical deadtime for the ZVS transition. The drain-to-source voltage and the gate-to-source voltage waveforms are shown in Fig.14 for both of the phases. It can be found that both of phases can achieve a ZVS turn-on with minimized switching loss, which verified the concept to simplify the control system.

The tested efficiency of the prototype is shown in Fig. 15. The peak efficiency of the prototype occurs at $6 \mathrm{~V}$ input, where also the voltage gain is the highest among all the scenarios. Beside, at the rated $12 \mathrm{~V}$ input, the efficiency of the prototype can achieve $97.45 \%$ with $4 \mathrm{~V} / 6$ A output. As a comparison, a single phase QSW buck converter is also built and tested at the same specification. It can be found that the efficiency can be improved by $5 \%$ with our design.

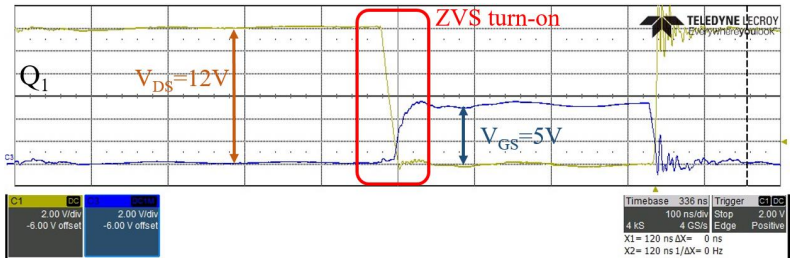

(a)

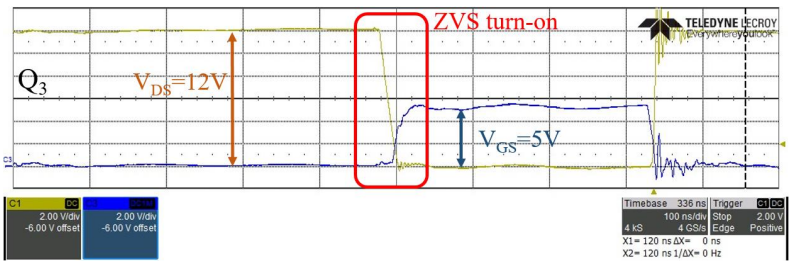

(b)

Fig. 14. Waveforms of drain-to-source and gate-to-source voltage of highside switches on the phototype (a) waveforms of Phase 1 (b) waveforms of Phase 2.

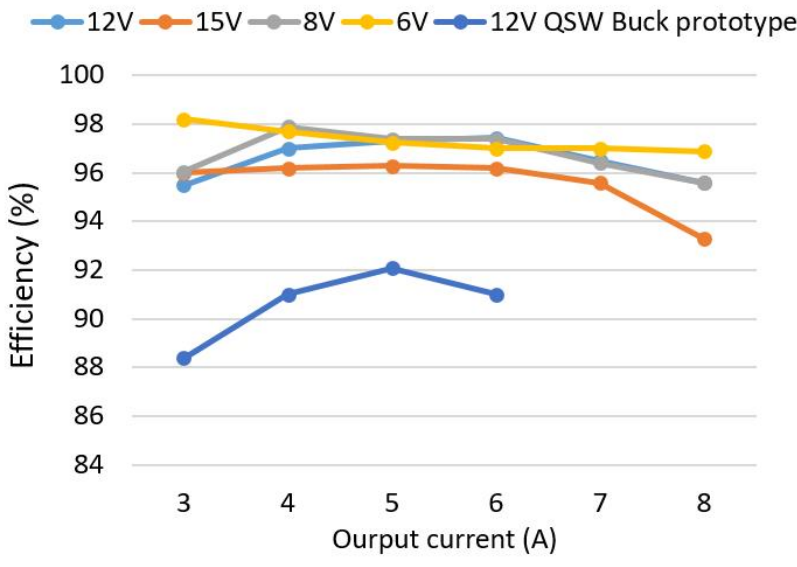

Fig. 15. Measuredefficiency of the prototype.

\section{CONCLUSION}

In this paper, a design of two-phase synchronous Buck converter is presented with an integrated planar magnetic components. By this design, the control of the converter can be simplified and the efficiency can be improved with distributed conduction current. The design procedures are verified by experimental results and the peak efficiency of the prototype achieves $97.45 \%$ at $4 \mathrm{~V} / 6$ A output.

\section{ACKNOWLEDGMENT}

The authors would like to thank Dr. Prasanth Thummala for technical discussion of the project and also would like to thank HITACHI Metal for providing ferrite core samples for the project.

\section{REFERENCES}

[1] J. Chen, F. Yang, C. Lai, Y. Hwang and R. Lee, "A High-Efficiency Multimode Li-Ion Battery Charger With Variable Current Source and Controlling Previous-Stage Supply Voltage," in IEEE Transactions on Industrial Electronics, vol. 56, no. 7, pp. 2469-2478, July 2009. 
[2] T. Huang, R. Peng, T. Tsai, K. Chen, and C. Wey, "Fast charging and high efficiency switching-based charger with continuous builtin resistance detection and automatic energy deliver control for portable electronics," IEEE Journal of Solid-State Circuits, vol. 49, no. 7, pp. 1580-1594, 2014

[3] Y. Liu, A. Kumar, D. Maksimovic and K. K. Afridi, "A High-PowerDensity High-Efficiency Three-Level Buck Converter for Cellphone Battery Charging Applications," 2018 IEEE Energy Conversion Congress and Exposition (ECCE), Portland, OR, 2018, pp. 5265-5270.

[4] Y. Liu, A. Kumar, S. Pervaiz, D. Maksimovic and K. K. Afridi, "A high-power-density low-profile DC-DC converter for cellphone battery charging applications," 2017 IEEE 18th Workshop on Control and Modeling for Power Electronics (COMPEL), Stanford, CA, 2017, pp. 1-6.

[5] Y. Dou, Z. Ouyang and M. A. E. Andersen, "High-Frequency GaNBased QSW Buck Converter with Coupled Inductor and Integrated Current-Balancing Transformer for Battery Fast Charging Application," PCIM Europe 2019; International Exhibition and Conference for Power Electronics, Intelligent Motion, Renewable Energy and Energy Management, Nuremberg, Germany, 2019, pp. 1-8.

[6] G. Gabian, B. Blalock and D. Costinett, "5V-to-4V integrated buck converter for battery charging applications with an on-chip decoupling capacitor," 2017 IEEE Applied Power Electronics Conference and Exposition (APEC), Tampa, FL, 2017, pp. 178-183.

[7] X. Huang, F. C. Lee, Q. Li and W. Du, "High-Frequency High-Efficiency GaN-Based Interleaved CRM Bidirectional Buck/Boost Converter with Inverse Coupled Inductor," in IEEE Transactions on Power Electronics, vol. 31, no. 6, pp. 4343-4352, June 2016.

[8] H. Xu, D. Chen, F. Xue and X. Li, "Optimal Design Method of Interleaved Boost PFC for Improving Efficiency from Switching Frequency, Boost Inductor, and Output Voltage," in IEEE Transactions on Power Electronics, vol. 34, no. 7, pp. 6088-6107, July 2019.

[9] Y. Dou, Z. Ouyang and M. A. E. Andersen, "Integrated Coupled Inductors with Functionality of Current Balancing Transformer for TwoPhase Synchronous DC-DC Converters," in IEEE Transactions on Power Electronics.

[10] X. Huang, T. Liu, B. Li, F. C. Lee and Q. Li, "Evaluation and applications of $600 \mathrm{~V} / 650 \mathrm{~V}$ enhancement-mode GaN devices," 2015 IEEE 3rd Workshop on Wide Bandgap Power Devices and Applications (WiPDA), Blacksburg, VA, 2015, pp. 113-118.

[11] Q. Li, Y. Dong, F. C. Lee and D. J. Gilham, "High-Density Low-Profile Coupled Inductor Design for Integrated Point-of-Load Converters," in IEEE Transactions on Power Electronics, vol. 28, no. 1, pp. 547-554, Jan. 2013.

[12] Hurley, William G., and Werner H. Wölfle,'Transformers and inductors for power electronics: Theory, design and applications," John Wiley Sons, 2013. 